\title{
A Formação do Espírito M andarim: As Implicações Sociopolíticas do Bacharelismo na Institucionalização do Judiciário Brasileiro
}

\author{
Anabelle Santos Lages* \\ Wendell Ficher Teixeira Assis**
}

Resumo

Revisitar a institucionalização do Poder Judiciário brasileiro implica reconhecer que categorias atualmente consideradas como indiscutíveis fazem parte de um desenrolar histórico. Não se trata de recontar a história, mas de demonstrar que a criação das faculdades de Direito consolida a predominância de determinados argumentos que culminaram por conferir uma legitimidade sociopolítica especial ao Poder Judiciário. Assim, com base na análise de jornais jurídico-políticos publicados entre 1840 e 1889, buscamos mapear os sentidos que caracterizam a constituição do campo jurídico, marcado pelos discursos da ciência, sacralidade e neutralidade, bem como identificar similaridades que ainda hoje orientam as decisões e posicionamentos do STF - Supremo Tribunal Federal. A noção de habitus acionada por Bourdieu (1989), que objetiva romper com a falsa dualidade que insiste em colocar em posições opostas indivíduo e sociedade, ajuda-nos na compreensão da posição ocupada pelos sujeitos jurídicos no cenário brasileiro.

Palavras-chave: institucionalização da justiça, bacharéis, magistratura, Supremo Tribunal Federal.

\footnotetext{
* Doutora em Sociologia. Bolsista PNPD do Programa de Pós-graduação em Sociologia da Universidade Federal de Alagoas.

** Doutor em Planejamento Urbano e Regional. Professor Adjunto do Instituto de Ciências Sociais da Universidade Federal de Alagoas. Pesquisador associado do Instituto de Pesquisa e Planejamento Urbano e Regional da Universidade Federal do Rio de Janeiro.
} 


\section{The Formation of the M andarin Spirit: The sociopolitical implications of bachelors in the institutionalization of the Brazilian judiciary}

Abstract

Revisit certain dimensions of the Brazilian judiciary involves initially recognize that indisputable categories considered were defined in a particular context. This is not to retell the story, but to demonstrate that the establishment of colleges and consequent legal field that arises from that consolidates the predominance of certain arguments that culminated to give a special legitimacy to the Judiciary in Brazil. Thus, based on the analysis of legal-political journals published between 1840 and 1889, we mapped the meanings that characterize the formation of the legal field, pronounced by discourses of science and sacredness, as well as identify similarities that still today guides decisions and positions of the brazilian Supreme Federal Court.

Keywords: bachelor, judiciary, Supreme Federal Court

\section{La formación del espíritu mandarín: las implicaciones sociopolíticas del bachillerismo en la institucionalización del poder judicial brasileño}

\section{Resumen}

Revisar la institucionalización del Poder Judicial brasileño implica reconocer que categorías actualmente consideradas como indiscutibles forman parte de un contexto histórico. No se trata de recontar la historia, sino de demostrar que la creación de las facultades de Derecho consolida la predominancia de determinados argumentos 
que culminaron por conferir una legitimidad especial al Poder Judicial en Brasil. Así, con base en el análisis de periódicos jurídico-políticos publicados entre 1840 y 1889, buscamos mapear los sentidos que caracterizan la constitución del campo jurídico, marcado por los discursos de la ciencia y de la sacralidad, así como identificar similitudes que aún hoy orientan las decisiones y posicionamientos del STF.

Palabras clave: institucionalización de la justicia, bachilleres, magistratura, Supremo Tribunal Federal

\section{Introdução}

Ao se analisar a formação dos bacharéis brasileiros, iniciada no século XIX e tida como suporte burocrático do Estado de Direito, percebemos que esta se imiscuiu no processo histórico que buscou elaborar projetos políticos para o Brasil. Revolver as construções edificadas ao longo desse transcurso evita que caiamos na "armadilha objetivista da reificação, naturalizando o caráter objetivado das estruturas e das instituições sociais" (Peters, 2013, p. 08), sobretudo, porque depois de consolidadas, tais construções operam em nós a crença de que sempre foi assim e de que elas sempre estiveram ali. Este tipo de raciocínio nos levaria a dar como certa e inquebrantável a ordem jurídica atual.

Entretanto, é exatamente pelo fato da institucionalização do Direito no país se confundir com o processo de construção sociopolítico brasileiro, que este artigo saúda uma aproximação entre a Sociologia e o Direito, ainda que isto não signifique uma identificação com a chamada "Sociologia do Direito" em seu sentido tradicional. Ao contrário, o que se compreende aqui é a existência de um processo social engendrado pela dinâmica histórica que reverbera no estabelecimento de um grupo específico de sujeitos que tiveram e ainda têm expressiva atuação no processo de conformação de nossas instituições. Revisitar certas dimensões do poder judiciário brasileiro implica, portanto, perceber o mundo social como algo estranho e não natural, tarefa imposta 
ao pesquisador que pretende escapar da armadilha de identificar a história deste campo com a "evolução" de seus conceitos e métodos e, assim, pensar mais claramente sobre o paradoxo intrínseco à produção da autonomia jurídica a partir da dependência em relação ao poder estatal (Chartier, 2002).

A perspectiva aqui delineada entende o Direito como produto sócio-histórico, por isto destacaremos as relações entre "Direito e sociedade" para além de um ponto de vista meramente abstrato, contemplando a necessidade de empreender um recorte que possibilite auxiliar na compreensão de um processo que tinha como principal objetivo a construção de uma sociedade "civilizada" (Neder, 1995). Com isto em mente e considerando o papel desempenhado pela imprensa no processo de divulgação de ideais e construção de consensos, principalmente na passagem do século XIX para o XX, mapeamos os discursos jurídicos veiculados em órgãos de comunicação da época. Para esta tarefa foram selecionadas três publicações: A Gazeta dos Tribunaes e A Gazeta Jurídica, ambas publicadas no Rio de Janeiro, respectivamente, entre 1840-1849 e 1873-1889, bem como o jornal Ensaio Jurídico e Litterario veiculado no Recife entre 1870 e $1879^{1}$.

A escolha desses periódicos, que cobrem um lapso de cinco décadas, fundamenta-se no fato de o periodismo jurídico não apenas estar inserido no debate historiográfico acerca das interpretações das leis e do papel dos bacharéis brasileiros, como ainda ter sido o principal lócus de divulgação do pensamento daqueles que desempenharam importantes funções em um momento de construção da cidadania e da formação de uma identi-

1 A eleição da temporalidade oitocentista justifica-se por ser um "contexto de emergência da ordem social competitiva na sociedade brasileira e da solidificação do liberalismo econômico e político como ideologia dos estratos sociais dominantes, saídos vitoriosamente da revolução descolonizadora" (Abreu, 1988, p.19). Ademais, após um longo domínio de orientação lusitana na formação do bacharelado nacional, o período compreende a criação das primeiras faculdades de direito no país e da fundação do Instituto dos Advogados Brasileiros (Wolkmer, 1997; Roberto, 2008). 
dade nacional (Ramos, 2010). Além disso, esses jornais de matiz jurídico-político fomentaram debates acerca da inescapável modernização e autonomização das instituições de controle social, como a judiciária, exatamente por ser um momento de construção de uma sociedade burguesa no Brasil que, como tal, requeria um sistema de justiça próprio, não mais dependente de Portugal (Neder, 1995). Essa dimensão já pode ser notada no discurso de posse do presidente do Instituto dos Advogados Brasileiros, que foi proferido em 1843 durante a cerimônia de fundação da entidade e publicado na Gazeta dos Tribunaes:

É tempo de encetar o Brasil essas grandes questões. Contando hoje 21 anos de existência, como povo livre, e independente; seria desairoso, que entrando, por assim dizer, em sua politica maioridade, ainda espaçasse o cumprimento da rigorosa obrigação em que está de promulgar as leis indispensáveis a sua felicidade [...]. Até hoje temos vivido sob a influencia de uma legislação, parte estrangeira, parte nacional, heterogênea às instituições juradas pela nação, própria só por isso mesmo para demorar nossa civilisação, retardar o engrandecimento de nossa indústria, e por consequência de nossa riqueza e opulência nacional (Gazeta dos Tribunaes, 1843, p. 04).

O regresso aos jornais do século XIX é um exercício teórico-metodológico que se coaduna à segunda parte deste artigo, que pretende identificar as similaridades e descontinuidades entre o discurso desse período de formação das instituições jurídicas e os pronunciamentos levados a cabo hoje na mais alta Corte brasileira: o STF - Supremo Tribunal Federal, instituição que desde sua origem procurou alocar os bacharéis em um lugar privilegiado na sociedade brasileira. Como se demostrará, com base no material analisado, por serem intérpretes coroados com uma aura de santidade laica, ao produzirem jurisprudência por meio de suas decisões, atuam diretamente na construção do direito e no apaziguamento dos conflitos, tais como os primeiros bacharéis brasileiros. 


\section{Colônia e M etrópole: Apontamentos de uma Simbiose}

A história do direito no Brasil começa em Portugal (Venâncio Filho, 1977). No século XVI, a Europa vivenciava momentos de profundas mudanças, período que coincide com os primeiros anos de colonização da principal possessão portuguesa. Alguns impactos da significativa mudança que se estabelecia no ambiente cultural europeu não apenas foram sentidos na Universidade de Coimbra, como também contribuíram para a maneira contraditória com a qual o Direito construiu sua hegemonia no Brasil. Se, por um lado, há uma exigência discursiva acerca do rigor e da cientificidade do Direito, por outro, a prática deste sempre foi caracterizada por certo "jeito brasileiro" de ser e ter as coisas resolvidas, geralmente, marcada por práticas de favor (Neder, 1995; Leal, 2012).

Uma possível explicação para o fato pode ser encontrada na forma com que o Iluminismo adentrou em Portugal, possuindo características distintas das ideias difundidas na França e em outros países da Europa. Ao contrário do Iluminismo francês, que carregava a ameaça à autoridade do rei, razão pela qual as obras de pensadores como Rousseau e Voltaire permaneceram proibidas em Portugal mesmo após a saída dos jesuítas ${ }^{2}$, o Iluminismo português era de natureza religiosa e não revolucionária; era reformista e nacionalista, essencialmente cristão e católico (Carvalho, 2008, p. 67). Neste sentido, ao mesmo tempo em que eram requeridos rigor e precisão no trato com as leis, bem como a defesa apaixonada pelo seu cumprimento, o tradicional sistema de ensino coimbrense - pautado na fé religiosa (Abreu,

2 Por considerá-lo politicamente perigoso, Coimbra evitou o contato de seus estudantes com o Iluminismo francês. Bernardo Pereira de Vasconcelos (formado em Coimbra no ano de 1816) fez interessante defesa por ocasião dos debates parlamentares acerca da criação dos cursos jurídicos: “O Direito de resistência, este baluarte da liberdade, era inteiramente proscrito; e desgraçado de quem dele se lembrasse! [...] [A Universidade de Coimbra] está inteiramente incomunicável com o resto do mundo científico. Ali não existe correspondência com outras academias; ali não se conferem graus senão àqueles que estudaram o ranço de seus compêndios" (Vasconcelos apud Carvalho, 2008, p. 85). 
1988) - e o sistema colonial-patrimonialista marcavam o modelo jurídico português, influenciando os comportamentos dos atores jurídicos na colônia. Essa ambiguidade típica do modus operandi da aplicação do Direito na sociedade portuguesa, que se espraiou pelo Brasil, é clarificada nos dois fragmentos dispostos a seguir, extraídos da Gazeta Jurídica e do Ensaio Jurídico e Litterário. Como se pode constatar, são discursos jurídicos que sustentam a racionalidade da lei, calcada em uma mentalidade científica, ao mesmo tempo em que atribuem ao bacharel um poder sacerdotal, marcado por preceitos divinos. Neste ponto, cabe lembrar que Tomás Gonzaga dedica todo o primeiro capítulo do seu "Tratado de Direito Natural" para provar a existência de Deus como princípio do direito natural.

O dever de instruir-se é para o juiz um preceito divino [...]. 0 magistrado que não possue os princípios da sciencia, acompanhando seus progressos, não pode ser o sacerdote sincero da lei: sacrificará nas aras sem comprehender os mysterios (Gazeta Jurídica, 1874, p. 467).

A lei não é filha do orgulho, da força bruta, de uma vontade altiva e caprichosa, ela é necessariamente um ato racional, expressão de uma verdade superior, elaborada pela razão, antes de ser intimada pela vontade. Só assim poderá a lei, verdadeiramente digna desse nome, ligar as consciências, unir os membros da sociedade sob seu império (Ensaio Jurídico e Litterário, 1878, n. 01, p. 05).

Foi dentro dessa ambiguidade entre racionalidade científica e iluminação divina, tendo como pano de fundo a urgência política por profissionais especializados para ocupar os quadros do aparelho administrativo estatal, que em 1827 foram criadas as faculdades de direito de São Paulo e de Olinda. Tudo isso ainda foi acompanhado pela chamada "profissionalização da política". De fato, como observou Neder, (1995), mais de 80\% dos graduados na Escola do Recife entre 1870 e 1930 empregaram-se no setor público, sendo que boa parte desses empregos nada tinha 
a ver com o Direito. Além disso, a própria intelectualidade brasileira na virada do século XIX era composta por bacharéis, o que lhes permitia participar ativamente do processo de construção da ordem burguesa no Brasil.

Notadamente, havia diferença entre as duas Escolas. Enquanto a de Olinda estava marcada pela ilustração, responsável por "erguer o espírito da população ao nível atingido pelos povos mais adiantados", no dizer de Clóvis Beviláqua (Neder, 1995, p. 102), a Faculdade de São Paulo era reconhecida mais por produzir um intelectual voltado para a prática política, moldado pelas ideias liberais, do que por fornecer um tipo de educação propriamente acadêmica, com vistas a formar teóricos e doutrinadores. Em comum às duas Escolas é o fato do liberalismo ter se tornado uma ideologia necessária à emancipação política e à organização do Estado no Brasil. Assim, tanto em São Paulo como em Recife a invocação dos preceitos liberais era uma constante, ainda que ironicamente permanecessem os privilégios de determinados seguimentos e mesmo a escravidão. De toda sorte, no Direito, a adoção do liberalismo implicava na formulação de normas jurídicas vocacionadas à neutralidade e à imparcialidade dos textos legais, as normas jurídicas positivas e os advogados deveriam conduzir o país ao rol das nações civilizadas (Neder, 1995, p. 107). Sobre este aspecto, os trechos apresentados a seguir, extraídos de jornais da época, demonstram tanto o clamor por reformas liberais, que haveriam de ser impulsionadas pela normatização das regras do Direito, quanto uma crítica aos fundamentos de incerteza que permeavam a aplicação da lei no território nacional:

Não cause estranheza a demora destas reformas. Alem de ser própria dos povos, que começam a vida politica e social é também uma condição das reformas liberaes. Tornar mais eficazes e promptas as garantias individuaes e o livre exercício de todas as liberdades, por meio de tribunaes que, em todas as localidades, executem e interpretem devidamente as leis, é desideratum tão liberal, quanto a reforma social do elemento servil (Gazeta Juridica, 1874, p. 442). 
No nosso paiz, produz-se o funesto resultado de não termos jurisprudência certa. Eis porque dizia um grave magistrado, ornamento de sua classe, que a administração da justiça no Brasil é o jogo de azar, parodiando sem duvida a satyra de Juvenal que enumerava entre os casos fortuitos a distribuição da Justiça (Gazeta Juridica, 1875, p. 452).

Eis, por tanto, demonstrada a necessidade dos advogados, isto é, de pessoas que versadas na legislação, nos costumes, usos, estyllos, tradicções e arestos, e fazendo de tal objecto a sua especial profissão, estejam em estado de preencher tão importante ministério (Gazeta do Tribunaes, 1843, p. 04).

O estabelecimento das duas Escolas de Direito ocasionado pela necessidade de formação de quadros técnicos cumpriu ainda um importante papel de unificação ideológica, principalmente quando se considera que praticamente toda a elite imperial graduou-se em Direito, contribuindo para a formação de uma entidade relativamente homogênea de conhecimentos e habilidades (Carvalho, 2008, p. 65). Ademais, a existência de somente duas faculdades de Direito no país facilitava o encontro entre estudantes das mais distintas regiões. Assim, depois de formados, juntamente com o diploma de bacharel, retornavam às suas cidades com a ideologia e as convicções adquiridas ao longo da formação jurídica. De acordo com Carvalho (2008, p. 72), “o preço da homogeneidade da elite brasileira foi uma distribuição muito mais elitista da educação e a menor difusão de ideias que os governos da época consideravam perigosas".

Se tomarmos a data da instituição dos cursos de Direito no Brasil é possível perceber que o campo jurídico, mesmo em sua gênese, nunca prescindiu do conflito, posto que a própria localização geográfica das escolas levava em conta questões estratégicas: São Paulo, berço dos Andradas e local simbolicamente poderoso em razão do Grito do Ipiranga, e Olinda, "viveiro de patriotas onde, na religião do martírio a mocidade brasileira viria também a aprender a liturgia do civismo" (Venâncio Filho, 1977, p. 80). 
Existe, portanto, uma coincidência temporal entre a derrota das armas brasileiras nos campos de Ituzaingó, defronte da Ilha de Martim Garcia e a criação das primeiras escolas. Ao que consta, o fracasso bélico produziu grande satisfação entre os civis, na medida em que desestimulou as ambições militares e proporcionou a abertura de novas carreiras. 0 "embate" entre militares e bacharéis se justifica pela importância que ambos assumiram logo no início do Império. No entanto, enquanto os primeiros corriam o risco de ser identificados com a guerra e o infortúnio, os segundos eram os elementos da estabilidade, da razão e da segurança. A construção desse sentido apaziguador a ser desempenhado pela magistratura brasileira pode ser inferida no fragmento disposto na sequência, que foi publicado na Gazeta Jurídica em 1874;

Em todas as épocas, os magistrados foram elementos de paz e segurança: os tyranos quando querem sangue, despedem a tóga e nomeam comissões militares: eis o elogio supremo da magistratura do nosso como de todos os paizes. A justiça no Brasil nasceu independente para constituir um elemento de protecção e grandeza (Gazeta Juridica, 1874, p. 364).

Sobre os cursos jurídicos, comentava Joaquim Nabuco, eram as antessalas da Câmara (Venâncio Filho, 1977) e, a despeito da ascensão de seu prestígio nos centros urbanos, seu impacto também reverberava pelo interior. Os jornais frequentemente publicavam notícias sobre "bacharéis" e "doutores, anunciando a emergência de um novo poder aristocrático" (Freyre, 1981). Um estudo feito pela University of California Press, The mandarins of Imperial Brazil (Eul-Soo; Seckinger, 1972) comparou os bacharéis em Direito aos mandarins: as duas elites tinham nas becas ricamente ornadas um primeiro elemento de semelhança e, tal qual os chineses, os bacharéis tinham o seu destino orquestrado por meio dos contatos estabelecidos entre as famílias; as relações políticas e econômicas do patriarca apontariam suas oportunidades no campo. Alguns recém-formados poderiam ser no- 
meados para ocupar cargos importantes no Império, entretanto, o usual era que o "mandarim" ocupasse primeiro as posições tidas como relativamente inferiores, como as de juiz municipal, promotor público, presidente de províncias e desembargador, por exemplo. Encerrado o début do treinamento político, a progressão na carreira iria depender dos atributos pessoais do bacharel, como personalidade, carisma, talento, relações matrimoniais etc. (Venâncio Filho, 1977; Leal, 2012).

Inegável o efeito de engrandecimento que a carreira jurídica produzia no sujeito, elevando-o a uma posição tão particular que quaisquer (e raras) diferenças de cor e econômicas ou preconceitos de origem, por exemplo, eram sublimadas, "fazendo ombrear nos postos brancos e mulatos, que adquiriram atestado de branquidade com a frequência nas escolas jurídicas, de medicina e, mais tarde, da academia militar" (Faoro, 1975, p. 93). 0 fascínio que as atividades do funcionalismo, propiciadas pelo anel de bacharel, exercia sobre as pessoas era tamanho que Joaquim Nabuco, num comentário jocoso, desafiou que se tomassem por acaso um punhado de brasileiros vindos de um lugar no qual se reunisse a sociedade mais culta: na eventualidade de não serem funcionários públicos, em algum momento já o teriam sido e, certamente, seus filhos se tornariam um (Nabuco apud Venâncio Filho, 1977). Além disso, o excesso de bacharéis "gerou o fenômeno repetidas vezes mencionado na época, a busca desesperada do emprego público por esses letrados sem ocupação" (Carvalho, 2008, p. 87).

Dentre as profissões liberais, o bacharel em Direito gozava de posição mais nobilitante, principalmente se considerarmos o desejo do país de deixar no passado posturas advindas do arbítrio e do privilégio e de aproximar-se de uma prática orientada para a aplicação de normas previamente prescritas e sem cunho pessoal. Nesta perspectiva, cabia ao jurista, apontado como o melhor intérprete, tanto a feitura como a aplicação das leis, restando aos militares, muitos deles oriundos de classes nobres, 
dar lugar à toga. Os assuntos de governo passaram então a ser tratados por especialistas, responsáveis por conferir neutralidade e técnica às decisões que pertenciam ao âmbito da política. A diferença é que ao ser compreendida "tecnicamente", ganhavam um "estatuto de verdade", saindo de uma discussão que poderia até então ser considerada marginalizada e adquirindo um caráter mais institucionalizado (Ramos, 2010, p. 84).

Nesse contexto, até mesmo a maneira dos julgamentos serem produzidos foi modificada. 0 que era velado, passou a ser público e os sentimentos de legitimidade daí decorrentes alcançavam a população em geral, fato que lhes permitia transferir para as instituições de Direito, em especial, aos magistrados, o manejo e a administração de suas vidas. 0 juiz passa a ser então o representante de um saber consciencioso. Ainda que vejamos a indicação de bacharéis-mandarins para cargos públicos como expressão de um imbricamento público-privado (Holanda, 1976), esta postura era propagada como sendo a expressão do interesse do cidadão e da justiça. A arte de governar a vida civil por intermédio da consolidação das instituições se instaura no cenário nacional, ao mesmo tempo em que se legitima o esclarecimento iluminado dos operadores do Direito como mecanismo de ampliação da justiça, ordem e da ciência. Isso pode ser inferido nos trechos transcritos a seguir que difundem a ideia de publicidade dos julgamentos, controle dos menos instruídos, respeito à indicação dos bacharéis e ao esclarecimento de suas consciências.

A publicidade dos julgamentos e da marcha dos processos é a alma da justiça, é a melhor garantia social, que mais contribui para que o povo se habitue a tomar interesse nos resultados das discussões e trabalhos judiciários, e para que ainda, os menos instruídos, conheçam por si a maneira porque se lhes administra sua vida, honra e fazenda (Gazeta dos Tribunaes, 1843, n. 01, p. 17).

Graves e sérios deveres impõem nos a carreira que abraçamos. Hoje nos iniciamos nos segredos da sciencia, investigamos a verdade, mediante os princípios do bom e do jus- 
to, amanhã seremos chamados a aplicar esse princípios, a defender ou a decidir, da fortuna, vida e honra de nossos concidadãos: e nesses solemnes momentos, Srs., por mais recta e pura que seja nossa consciência, se não for esclarecida, quão facilmente comprometteremos a justiça e sacrificaremos a inocência (Ensaio Juridico: Jornal Academico, 1863, n. 01, p. 03).

A noção de habitus trazida por Bourdieu (1989), que objetiva romper com a falsa dualidade que insiste em colocar em posições opostas o indivíduo e a sociedade (Wacquant, 2007), ajuda-nos a melhor compreender a posição ocupada pelos bacharéis no cenário brasileiro da época. Com esse conceito, o sociólogo pretende captar o processo que designou por "interiorização da exterioridade e exteriorização da interioridade" (Bourdieu, 1983, p. 47), o que significa que a sociedade encontra-se incorporada nas pessoas "sob a forma de disposições duráveis, ou capacidades treinadas e propensões estruturadas para pensar, sentir e agir de modos determinados, que então as guiam nas suas respostas criativas aos constrangimentos e solicitações do seu meio social existente" (Wacquant, 2007, p. 65).

Como a constituição do habitus jurídico não estava restrita ao processo de formação e à profissionalização dos bacharéis, "os controles administrativos existentes e dirigidos para a normalização do ensino jurídico no Império, tanto quanto as doutrinas difundidas em sala de aula poderiam prescindir de um caráter essencial" (Abreu, 1988, p. 236). Neste sentido, foram o ambiente extracurricular, a agitada vida acadêmica, a capacidade oratória, as vestes, mas não necessariamente o conhecimento jurídico, os responsáveis por constituir as disposições específicas de um bacharel. Observou-se, portanto, um interessante movimento (intencional ou não) por parte do Estado patrimonial brasileiro consistente "em despolitizar a sala de aula e, em contrapartida, politizar a vida extracurricular" (Abreu, 1988, p. 236). A propagação desse sentido distintivo envergado pelos bacharéis é notória no fragmento apresentado abaixo extraído da 
Gazeta Jurídica. 0 texto constrói uma aura de superioridade que se inicia com o título, transbordando para o léxico para atingir o pronome de tratamento e os adornos da vestimenta:

Como o quer a Lei, a acusação tem de ser sustentada por homem eminente, que se chama o órgão da Lei e da sociedade e que deve ser o mais distincto por suas luzes e sua aptidão oratória, tendo o título, as vestes, as attribuições, o tratamento, a graduação hierarchica, em uma palavra, toda a importância judiciaria que lhe deve ser própria (Gazeta Juridica, 1873, p. 96).

Havia ainda uma íntima relação de solidariedade entre os bacharéis e os interesses dos grandes proprietários rurais (Abreu, 1988, Leal, 2012). Tais interesses estavam adstritos à monocultura e à mão de obra escrava, principalmente quando se reconhece que grande parte dos bacharéis estava marcada pela vida interiorana, economicamente privilegiada e vinculada ao chamado "mandonismo local". Conforme demonstrado em estudo realizado por Carvalho (2008), cerca de 50\% dos magistrados e advogados tinham, direta ou indiretamente, algum vínculo com a propriedade rural e uma porcentagem menor com o comércio. Por essa razão, quando se afirma que "as academias de direito foram responsáveis por uma prática pedagógica de tal modo comprometida com os processos de exploração econômica e de dominação política" (Abreu, 1988, p. 237), não há como ignorar em paralelo a existência de uma estrutura legal-burocrática que se valia da política para despolitizar a formação jurídica, já que ela transcendia as paredes das salas de aula. Ao contrário, pode-se inferir que os interesses em disputa fora do campo jurídico estruturavam e eram estruturados pela própria instituição que se formava (Bourdieu, 1989).

Em específico, no que diz respeito aos magistrados, a socialização e o treinamento introduzidos em suas carreiras incorporavam em seu habitus "propensões estruturadas para pensar, sentir e agir" (Wac- 
quant, 2007, p. 65) conforme as solicitações e constrangimentos operados pelo Estado. Sendo dialética, essa relação entre a situação e as disposições adquiridas pelo juiz conformava também um tipo específico de Estado. Além disso, "num país geograficamente tão diversificado e tão pouco integrado, onde pressões regionalistas se faziam sentir com frequência, a ampla circulação geográfica da liderança tinha um efeito unificador poderoso" (Carvalho, 2008, p. 124). Os magistrados, agora também políticos, possuíam um poder de construção de determinada realidade que os autorizava a estabelecer quais os sentidos seriam considerados válidos no mundo social; faziam isto a partir dos cânones da ciência, poder simbólico cujo exercício só é possível a partir da "aquiescência" daqueles que lhes estão submetidos e daqueles que nem mesmo sabem que o exercem (Bourdieu, 1989). A fabricação desse consenso, unidimensional e apaziguador, pode ser depreendida dos fragmentos a seguir, ambos publicados na Gazeta Jurídica, respectivamente em 1880 e 1873:

Quando esses juízes, embora muitos sejam poderosa arma política na localidade, desprezam seus negócios e desenvolvem uma dignidade e imparcialidade em suas decisões fundadas na razão e justiça, os seus concidadão vivem satisfeitos, obedientes e se sujeitam a elles com gosto e veneração (Gazeta Juridica, 1880, n.29, p. 227).

0 que é verdade e sempre é que, se for considerada a gravidade dos interesses sobre os quaes a magistratura exerce sua acção, e as condições que exige o seu serviço, está ella na primeira ordem das carreiras onde importa impedir a entrada à ignorância e à indignidade, e abrir exclusivamente as portas à sciencia e à integridade bem provadas (Gazeta Jurídica, 1873, n.24, p. 20).

O que não se via, entretanto, era um comportamento voltado para o povo em geral. 0 que fizeram foi promover ainda mais uma homogeneidade político-ideológica entre seus pares, consolidando o que Faoro (1975) denominou de estamento e, como tal, autorizados a receber e fruir dos benefícios e regalos pró- 
prios desta condição. 0 discurso dos bacharéis ajudava também a desenvolver e consolidar as estruturas que surgiram com a promulgação do Estado Nacional (Faoro, 1975). Por sua vez, os caminhos percorridos pela magistratura objetivavam uma maior aproximação do estamento político que, em um último sentido, "representa um segmento que se apropria do Estado, sem condescendência com a presumível vontade do povo" (Faoro, 1975, p. 89). Neste sentido, parlamentares, magistrados, senadores, funcionários públicos adquiriam, numa "terra de advogados, onde apenas os cidadãos formados em Direito [ascendiam] em regra às mais altas posições e cargos públicos" (Holanda, 1995, p. 156), o chamado vício do bacharelismo, por meio do qual a minoria dirigia, controlava e infundia seus padrões de conduta à maioria (Faoro, 1975). Interessante notar que a atuação dos bacharéis na administração estatal não ocorreu apenas nas instituições de comando de maior hierarquia; ao "pequeno intelectual" cumpria auxiliar no desenvolvimento das estruturas de poder nos gabinetes provinciais e municipais. Essa capilaridade da presença dos bacharéis nas instituições públicas fica evidente no trecho transcrito a seguir, publicado em 1843 na Gazeta dos Tribunaes:

Della sahiram muitas vezes magistrados distictos pela sua illustração e probidade. Encontraram-se nella sempre sábios mui ilustres, cuja vastidão de conhecimentos abrangia todos os campos do direito [...] versados em solida philosofia e d'uma erudição espantosa, a ordem dos nossos advogados tem sido digna de occupar lugar mui disticto na republica das letras. [...] 0 povo deparado com mui dignos de sua confiança para os lugares de primeiros funccionários públicos. Quantos membros do poder executivo, quantos embaixadores, senadores, deputados, presidentes de povincia, etc., etc., tem pertencido a disticta ordem dos advogados? (Gazeta dos Tribunaes, 1843, p. 05).

De acordo com Abreu (1988), juízes, parlamentares e funcionários com formação jurídica passaram a dominar o Estado brasi- 
leiro, sendo que os cargos no judiciário, executivo e legislativo eram ocupados majoritariamente pelos bacharéis. A junção entre interesse público e privado passou, ao menos em tese, a ser mediada pelo bacharel. A "consciência nacionalista", viabilizada pelo aparecimento desse corpo coeso, tinha seu alicerce numa racionalidade ético-jurídica perpassada pelas teorias do liberalismo (Neder, 1995); era, afinal, "um produto coletivo e coletivamente apropriado que servia a interesses particulares tendentes a se apresentarem como desejos universais ao conjunto do grupo" (Bourdieu, 1989, p. 10).

Esse resgate histórico ajuda a tornar visível a autoridade mística que emerge dos grandes discursos presentes na estrutura jurídica, bem como a formação do habitus (Bourdieu, 1989) ou identidades coletivas (Strauss, 1999) de uma classe, deixando à mostra o caráter arbitrário do Direito, construído sobre camadas textuais interpretáveis e transformáveis. 0 Direito, assim como a arte e a religião, é um sistema simbólico que, como instrumento de comunicação e de conhecimento, cumpre a função de legitimação do poder. As relações por ele estabelecidas são sempre relações de poder, ou seja, dependem do poder material ou simbólico acumulado pelos agentes ou instituições envolvidas (Bourdieu, 1989, p. 12).

0 retorno ao que chamamos aqui de dimensão simbólica do campo jurídico brasileiro não pretende transpor dois séculos e equiparar de maneira imediata o ambiente imperial com contornos mais recentes da Suprema Corte Brasileira. Não se trata de recontar a história, mas de perceber similaridades discursivas e de classe entre o estabelecimento da instituição jurídica no país, ocorrido na passagem do século XIX para o XX e propiciado pela criação de Escolas de Direito, e uma simbologia que ajuda na compreensão do que representa hoje o Supremo Tribunal Federal. Como se verá, em comum as ideias de razão, técnica e sacralidade acompanham tanto a justificativa para a consolidação do bacharelismo no Brasil como a própria razão de ser do STF. A 
ideia dos bacharéis-mandarins se reatualiza no poder encarnado pelo STF, todo o simbolismo, sacralidade, capacidade técnica e neutralidade, que hoje pairam sobre as togas dos ministros, reverberam o processo de institucionalização do campo jurídico iniciado com a abertura das faculdades de Direito onde se formaram, ao mesmo tempo, os primeiros bacharéis e o espírito de superioridade de mando.

\section{Supremo T ribunal Federal: Ciência e Sacralidade reatualizados na contemporaneidade}

As transmissões ao vivo dos julgamentos pela TV Justiça e a frequência praticamente diária nos noticiários e jornais não deixam dúvidas: eles são especiais. De acordo com Lahire (2002), assim como acontece com o nome próprio, a toga sobre seus ombros funciona como um direcionamento afetivo em relação ao qual há uma identificação simbólica dos seus portadores. Embora a roupa utilizada nos julgamentos seja comumente chamada de toga, o texto original do regimento interno do Supremo Tribunal Federal, datado de 27 de outubro de 1980, mantém intacto (mesmo após as 51 emendas regimentais ocorridas desde a sua publicação) o parágrafo único do artigo 16, que trata sobre as vestes talares. Juntamente com a determinação do pronome de tratamento adequado, a norma determina o uso da indumentária pelos ministros:

Art. 16. Os ministros têm as prerrogativas, garantias, direitos e incompatibilidades inerentes ao exercício da magistratura.

Parágrafo único. Receberão o tratamento de Excelência, conservando o título e as honras correspondentes, mesmo após a aposentadoria, e usarão vestes talares, nas sessões solenes, e capas, nas sessões ordinárias ou extraordinárias (STF, 2017).

É possível localizar tais regulamentações já no artigo 222 da Lei 1030, de 14 de novembro de 1890, na qual o general Manoel 
Deodoro da Fonseca, Chefe do Governo Provisório da República, decretou:

Art. 222. A denominação, tratamento honorifico e distinctivos dos membros do Supremo Tribunal Federal serão os mesmos dos actuaes ministros do Supremo Tribunal de Justiça, observado o disposto no decreto n. 25 de 30 de novembro de 1889 que continúa a ser applicavel aos juizes do districto federal, assim como o tratamento de que gozam e as insignias de que devem usar nos actos publicos (Brasil, 1890).

A pesquisa destinada a conhecer o estabelecimento do uso da toga pelos magistrados nos levou a identificar nesta prática aquilo que Hobsbawm e Ranger (2002) chamaram de "tradição inventada". Ainda que não retornemos à Roma Antiga, não restam dúvidas que, no Brasil, a indumentária tem sido formal e repetidamente institucionalizada ao longo dos anos. Observa-se que a cada nova situação política vivenciada no país, ocorria uma imediata reação com vistas a reafirmar o seu uso, "estabelecendo seu próprio passado através da repetição quase que obrigatória da norma" (Hobsbawm e Ranger, 2002, p. 11), seja ela em forma de lei, decreto, seja regimento interno. A "tentativa de estruturar de maneira imutável e invariável” (Hobsbawm e Ranger, 2002, p. 11) as vestes como figuração distintiva dos magistrados pôde ser observada em momentos de extinção e criação de tribunais. Assim se deu com o fechamento dos Tribunais de Relação do Império e a subsequente instituição da Justiça Local do Distrito Federal; o decreto 9.263, de 28 de dezembro de 1911, no art. 89, n. I, prescreveu aos desembargadores da Corte de Apelação e aos juízes de direito o uso, nas sessões e audiências das câmaras e júri, o vestuário marcado no decreto 1.326, de 10 de fevereiro de 1854. Igualmente, o decreto n. 16.273, de 20 de dezembro de 1923, tornou obrigatório para os magistrados e membros do Ministério Público, no art. 256, parágrafo 2ํㅜ o uso do vestuário prescrito no art. 89 do citado decreto 9.263/1911. Para dirimir 
quaisquer dúvidas sobre o traje, também foram estabelecidas normas, como o decreto 24.236, de 14 de maio de 1934, assinado pelo presidente Getúlio Vargas.

Hobsbawm e Ranger (2002, p. 11) utilizam justamente a atividade judicante para diferenciar a "tradição" do "costume": "'costume' é o que fazem os juízes; 'tradição' (no caso, tradição inventada) é a peruca, a toga e outros acessórios e rituais formais que cercam a substância, que é a ação do magistrado". Para o ministro Mário Guimarães: a "toga, pela sua tradição e seu prestígio, é mais do que um distintivo, é um símbolo. Alerta, no juiz, a lembrança de seu sacerdócio. E incute no povo, pela solenidade, respeito maior aos atos judiciários" (Guimarães, 1958, p. 195). Como vimos anteriormente nos jornais do período de institucionalização do judiciário, a toga é representada como signo da pacificação, da ordem, da ciência, da neutralidade iluminada sendo ainda associada à mística religiosa.

A despeito desses rituais não possuírem em si algum elemento substantivo que influencie ou determine de forma objetiva a função de julgar, à qual os ministros estão adstritos, os discursos jurídicos deles advindos informa um ofício que se apresenta como sagrado e, como tal, vinculado à esfera religiosa. Aquele que possui essa missão "carrega o sacrário no qual se guarda a fé na Justiça e, mais que tudo, a esperança no justo viver com o outro", como disse a Ministra Cármen Lúcia Antunes Rocha em seu discurso de posse como Presidenta do STF (Rocha, 2017, p. 09). Isso nos faz perceber que a viabilidade da sociedade não está vinculada ao seu caráter absolutamente racional, intelectualizado, "mesmo nosso pensamento racional autoconsciente deve basear-se em alguns processos não racionais" (Collins, 1982, p. 27). Neste sentido, o Supremo Tribunal Federal constrói sua imagem institucional como entidade apta a realizar "a travessia para tempos pacificados, travessia em águas em revolto e cidadãos em revolta. A busca pela Justiça [...] põe-se como bússola a impor que se persista na tentativa de se alcançar alguma calma- 
ria" (Rocha, 2017, p. 05). No passado e na atualidade, a ordem do discurso jurídico apresenta continuidades e repetições que dotam o exercício da magistratura de uma atmosfera transcendental, tanto nos jornais do período de institucionalização quanto nas modernas transmissões das sessões do STF, abundam as caracterizações que ornam os operadores do direito de características especiais, quase como se fossem deuses cegos e imparciais da fabricação da justiça. Esta caracterização distintiva também pode ser identificada no pronunciamento do ministro Marco Aurélio Melo apresentado a seguir, que recorre à noção religiosa de unção para caracterizar a atuação dos magistrados:

\footnotetext{
O Ministro do Supremo Tribunal Federal (...) não ocupa uma cadeira de forma balizada no tempo. Ele é vitalício naquela cadeira. Então, ele se encontra praticamente ungido para exercer essa missão sublime, que é julgar o próprio semelhante e os conflitos de interesses que envolvam os semelhantes (Mello, 2015, p. 24).
}

A imagem quase bíblica de uma travessia, utilizada pela presidente do STF, faz recordar a teoria durkheimiana sobre a religião, preocupada em saber não apenas sobre as crenças que as mobilizam, mas sobre o papel desempenhado pelos rituais sociais realizados por seus membros; tomar a religião como um fenômeno não racional nos ajuda a compreender os desdobramentos morais e as ideias simbólicas mobilizadas pelos rituais sociais (Durkheim, 1996). Collins (1982) sustenta que as aplicações dessa teoria vão além da esfera religiosa, contribuindo para a explicação das ideologias políticas, bem como sobre os setores seculares da vida moderna, ligando as condutas do cotidiano às práticas e crenças religiosas primitivas. A observação dos elementos que compõem o fenômeno religioso favorece o alcance de um modelo geral de ritos sociais. Por outro lado, como visto na primeira parte deste artigo, o processo de formação do pensamento jurídico brasileiro se deu juntamente com os interesses históricos de um tempo, ele é a marca de um período que ambi- 
cionava o estabelecimento de instituições jurídicas, aptas a se apresentarem como científicas e neutras de forma a conduzir o Brasil para o rol das "nações civilizadas" (Neder, 1995).

O discurso jurídico que sustenta a missão dos julgadores do século XIX e do século XXI continua sendo a superação da barbárie e da irreflexão por meio da ciência jurídica. Como se pode constatar nos fragmentos transcritos a seguir, o primeiro publicado na Gazeta Jurídica em 1843 e o segundo proferido durante posse da presidenta do STF em 2016, mesmo tendo se passado quase dois séculos, permanecem as noções que apresentam a aplicação da justiça como forma de superação dos conflitos e alcance de uma civilização pacífica.

Não é excitando ódios e paixões que se poderão chamar a ordem às decisões judiciarias; entendemos antes que, sem deixar de lamentar esses males que a ignorância, o erro, a maldade, as prevaricações, e até mesmo as omissões dos juízes causam a justiça, devemos, todavia, esperar que o progresso das luzes, o crescente desenvolvimento de patriotismo pelo gozo de um governo constitucional, e sobre tudo, uma legislação bem adequada às precisões da nação, venham em pouco tempo collocar-nos a par desses maravilhosos melhoramentos da civilisação (Gazeta dos Tribunaes, 1843, n.01, p. 01).

Guardar e fazer garantir a satisfação do sentimento de Justiça de cada um e de todos os brasileiros como juíza constitucional é tarefa tão grata quanto difícil. É compromisso que não tem fim. Compromisso, reconheça-se, nem sempre bem-sucedido. Quase nunca bem entendido. É apenas compromisso imprescindível como forma única de superação da barbárie (Rocha, 2017, p. 04).

Essa união entre sacralidade e ciência que norteou o bacharelismo brasileiro, também pode ser percebida na atividade judicante do STF e fornece-nos elementos que ajudam a compreender recorrentes declarações de ministros que afirmam julgar somente de acordo com sua "ciência e consciência", como costuma dizer o 
ministro Marco Aurélio Mello ${ }^{3}$. A metodologia de julgamento exposta pelo Ministro, acionando os princípios de sua consciência sem escapar ao rigor da ciência, também aparece como requisito para a nomeação dos magistrados pelo Poder Executivo no final do século XIX, quando a escolha é justificada como sendo do interesse do cidadão e orientada pelo saber e consciência da lei envergada pelo magistrado:

A tal respeito, admitimos sem dificuldade que, a nomeação de magistrados, pelo Poder Executivo, nas vistas da nossa sabia Constituição, não foi consentida em favor dos próprios nomeados, mas creada no interesse dos cidadãos, para que tenha a certeza de que o magistrado, a cuja escolha presidio a solicitude do Governo, é o representante do saber, da consciência e da Lei de que é elle o único órgão (Gazeta Jurídica, 1873, n. 01, p. 80).

De toda forma, a institucionalização de um poder científico pretendia fazer com que o direito fosse um "dispositivo estabilizável, estatutário e calculável, um sistema de prescrições regulamentadas e codificadas" (Rodrigues, 2012, p. 147), ainda que as decisões fossem apenas quimericamente revestidas com uma aparência de julgamento, conforme se pode notar em texto publicado na Gazeta Juridica em 1873:

A primeira condição, por conseguinte, que se deve impor ao nosso Superior Tribunal de Justiça é que, quando firmar jurisprudência, por seu Assento, o faça por modo que se diga revestido de fórmulas que lhe deem a aparência de julgamento (Gazeta Juridica, 1873, n. 01, p.15).

3 Curiosamente, o tema do disciplinamento da consciência aparece em um artigo publicado na Gazeta Jurídica em 1874, sustentando a impossibilidade de se diferenciar os atos da ciência dos da consciência. "Não se pode, sob boas razões, em processo criminal de julgamento, pretender distinguir o acto da sciencia do da consciência, por que, quem intervem no processo por qualquer modo, é parte nelle e, como tal, não tem a necessária imparcialidade que a lei requer para decidir sobre a causa do acusado" (Gazeta Juridica, 1874, n. 02, p. 471). 
A prescrição acima não está muito distante do método utilizado pelo Ministro do Supremo Tribunal Federal, Marco Aurélio Mello, que afirma que quando do julgamento de uma matéria, operacionaliza sua decisão da seguinte maneira: "idealizo para o caso concreto a solução mais justa e posteriormente vou ao arcabouço normativo, vou à dogmática buscar o apoio" (Mello, 2015, p. 112). Tais discursos mostram traços de certo fetichismo jurídico, "jogos que se fazem esquecer como jogos" (Pachukanis, 1988), que acompanham os discursos jurídicos e são legitimados pelas próprias instituições de justiça. No campo jurídico a produção simbólico-material de decisões necessita ser, ao menos aparentemente, apresentada como expressão líquida e certa do racionalismo neutro da lei. A esse respeito, Pachukanis (1988) argumenta que o Estado jurídico é uma miragem que muito convém à burguesia, uma vez que substitui a ideologia religiosa em decomposição e esconde aos olhos das massas a realidade do domínio burguês. A ideologia do Estado jurídico convém mais ainda do que a ideologia religiosa porque não reflete completamente a realidade objetiva ainda que se apoie nela. A indicação de pessoas com "notável saber jurídico", comprometidas com um julgamento exclusivamente técnico, neutro, quase sacro e constitucional, faz parte da construção de uma realidade ficcional e quimérica, na qual tanto ministros quanto os "sujeitos de direito" acreditam na possibilidade de um julgamento não político e/ou ideológico. Tratando-se do Supremo Tribunal Federal, responsável pela proteção da Constituição, a dificuldade de perceber a impossibilidade disto torna-se ainda maior e suscita denúncias e/ou críticas de que a decisão ou determinado ministro não estaria consonante a um preceito maior. Explicando melhor, acredita-se que realmente seja possível julgar exclusivamente conforme a lei, deixando de lado quaisquer pressupostos da esfera subjetivo-política.

Quando um ministro acusa o outro de não julgar conforme a Constituição ou de estar sendo parcial, reforça-se a crença de que seria possível fazê-lo. Alguns elementos (ou discursos) que se encontram, como vimos nos jornais do século XIX, na gêne- 
se de formação do campo jurídico propiciam a difusão dessa miragem-real. Consideramos, em específico, que o princípio da igualdade jurídica, o respeito às normas constitucionais e a proteção ao chamado Estado Democrático de Direito são retóricas que acompanham os participantes do jogo social e compõem a sua illusio (Bourdieu, 2001). No entanto, igualdade e democracia não residem num sistema de normas jurídicas, ao contrário, são um construto sempre inacabado, amarradas às iniciativas de indivíduos ou grupos que se posicionam contra a ordem estabelecida. Neste sentido, tais discursos institucionalizados, mas vazios de legitimidade verdadeiramente democrática, indicam que o totalitarismo e a democracia não são necessariamente opostos.

\section{Breves reflexões finais}

$\mathrm{O}$ artigo foi dividido em duas partes que se comunicam. Na primeira parte, a história social da emergência do campo jurídico brasileiro, feita a partir de alguns estudos já publicados sobre o tema, juntamente com o retorno aos periódicos jurídicos da época, auxiliaram na desconstrução da autonomia absoluta do Direito, que funciona como amálgama das ideias de neutralidade e universalidade, reeditadas sempre que a atividade de julgar entra em pauta. Além disso, mostrou como o discurso de ciência e sacralidade involucrados no ofício dos bacharéis, em especial, dos magistrados, reedita-se e se reatualiza na atuação do Supremo Tribunal Federal.

Longe de recontar a história do judiciário brasileiro, nossa tarefa foi traçar as similaridades prático-discursivas e de classe que nortearam o estabelecimento da instituição jurídica no país, ocorrido na passagem do século XIX para o XX, reconectando-as com a simbologia mítica e neutral que caracteriza a atuação do Supremo Tribunal Federal na atualidade. Como se espera ter sido demonstrado, as ideias de razão, técnica e sacralidade acompanham tanto a justificativa para a consolidação do bacha- 
relismo no Brasil como a própria razão de ser do STF. A ideia dos bacharéis-mandarins se reatualiza no poder encarnado pelo STF; o simbolismo, sacralidade, capacidade técnica e neutralidade, que hoje pairam sobre as togas dos ministros, reverberam o processo de institucionalização do campo jurídico iniciado com a abertura das faculdades de Direito onde se formaram, ao mesmo tempo, os primeiros bacharéis e o espírito de superioridade de mando. No passado e na atualidade, a ordem do discurso jurídico apresenta continuidades e repetições que dotam o exercício da magistratura de uma atmosfera especial, tanto nos jornais do período de institucionalização quanto nas modernas transmissões das sessões do STF estão presentes elementos que ornam os operadores do direito de características especiais, apresentando-os como sujeitos imparciais de fabricação da justiça.

A neutralidade científica acionada como garantia da justiça e da manutenção do Estado de Direito se adorna no caso brasileiro com uma aura sacramental-religiosa culminando em uma síntese que se expressa como uma fé na ciência do Direito. Na trilha deste raciocínio, procuramos evidenciar como a formação do campo jurídico nacional repercutiu e continua repercutindo na forma e no conteúdo das decisões jurídicas, bem como produzindo uma ideia quimérica de rigor apolítico e meramente técnico. Produz-se desta forma uma negação política da dimensão política, que recobre a atuação do poder judiciário desde sua institucionalização. Assim sendo, uma ordem prático-simbólica se erige como condição de possibilidade de uma atuação sempre norteada por parâmetros científicos não afeitos a decisões casuísticas ou aos jogos de interesses. Desta forma, reatualiza-se na atuação do STF a trajetória do campo jurídico brasileiro, que reflete o problema das decisões judicialmente tomadas sobre questões políticas ou decisões politicamente negociadas sobre questões essencialmente jurídicas. Como sugere Rancière (2010), despolitizar tem sido o mais antigo dos trabalhos da esfera política e a prática jurídica nacional pode ser tomada como um espaço de reverberação desta prática. 


\section{Referências}

Abreu, Sérgio França Adorno. Os Aprendizes do Poder: o bacharelismo liberal na política brasileira. Rio de Janeiro: Paz e Terra, 1988.

Bourdieu, Pierre. Sociologia. In: Ortiz, Renato (Org.). Coleção Grandes Cientistas Sociais, n. 39. São Paulo: Ática, 1983.

Bourdieu, Pierre. O Poder Simbólico. Rio de Janeiro: Bertrand Brasil, 1989.

Brasil. Decreto n. 1030, de 14 de novembro de 1890. Disponível em http:// www.planalto.gov.br/ccivil_03/decreto/1851-1899/D1030.htm. Acesso em abril de 2014.

Carvalho, Jose Murilo de. Cidadania no Brasil: o longo caminho. 10. ed. Rio de Janeiro: Civilização Brasileira, 2008.

Collins, Randall. The Sociology of God. In: Collins, Randall. Sociological Insight: an introduction to non-obvious Sociology. Trad. Tania Quintaneiro. New York: Oxford University Press, 1982.

Chartier, Roger. Pierre Bourdieu e a História: debate com José Sérgio Leite Lopes. Topoi, Rio de Janeiro, 2002.

Eul-Soo, Pang; Seckinger, Ron L. The Mandarins of Imperial Brazil. In: Comparative Studies in Society and History, v. 14, n. 2, mar, pp. 215-244. Cambridge University. Disponível em: http://www.jstor.org/action/showPublicati on?journalCode=compstudsocihist, 1972. Acesso em: 22 abr. 2011.

Faoro, Raymundo. Os Donos do Poder: formação do patronato político brasileiro. 2. ed. rev. e aum. Porto Alegre: Globo; São Paulo: Ed.USP, 1975.

Hobsbawm, E. J.; Ranger, T. O. A Invenção das Tradições. 3. ed. Rio de Janeiro: Paz e Terra, 2002.

Holanda, Sérgio Buarque de. História Geral da Civilização Brasileira. 7 ed. Rio de Janeiro: Bertrand Brasil, 1975.

. Raízes do Brasil. 26. ed. São Paulo: Companhia das Letras, 1995.

Leal, Victor Nunes. Coronelismo, Enxada e Voto: o município e o regime representativo no Brasil. 4. ed. São Paulo: Companhia das Letras, 2012.

Mello, Marco Aurélio. Ministro Marco Aurélio: vinte e cinco anos no STF. Brasília. Disponível em: http://www.stf.jus.br/arquivo/cms/publicacaoPublicacaoInstitucionalComemoracoes/anexo/Ministro_Marco_Aurelio_25_anos_ no_STF.pdf, 2015. Acesso em agosto de 2017. 
Neder, Gizlene. Discurso Jurídico e Ordem Burguesa no Brasil. Porto Alegre: Sérgio Antônio Fabris Editor, 1995.

Rancière, Jacques. En los bordes de lo político. Buenos Aires: Ediciones La Cebra, 2010.

Peters, Gabriel. 2013. Habitus, Reflexividade e o Problema do Neo-objetivismo na Teoria da Prática de Pierre Bourdieu. Disponível em: https:// www.academia.edu/1630046/Habitus_reflexividade_e_neo-objetivismo_na_ teoria_da_pratica_de_Pierre_Bourdieu. Acesso em: 10 nov. 2013.

Roberto, Giordano Bruno Soares; Fiuza, César. 0 Direito Civil nas Academias Jurídicas do Império. $602 \mathrm{f}$. Tese de doutorado - Universidade Federal de Minas Gerais, Faculdade de Direito. Disponível em: http://hdl.handle.net/1843/ DIRE-7PYKYE. Acesso em: 30 jul. 2012, 2008.

Rodrigues, Carla. Fenomenologia e Direito. Cadernos da EMARF, Rio de Janeiro, v. 5, n. 1, pp.1-150, abr./set, 2012.

Rocha, Cármen Lúcia Antunes. Discurso de posse Ministra Cármen Lúcia. Disponível em: http://www.stf.jus.br/arquivo/cms/noticiaNoticiaStf/anexo/DiscursoPosseMCL.pdf, 2016. Acesso em agosto de 2017.

Supremo Tribunal Federal. Regimento Interno do Supremo Tribunal Federal. Disponível em: http://www.stf.jus.br/arquivo/cms/legislacaoRegimentoInterno/anexo/RISTF.pdf, 1980. Acesso em maio de 2013.

Supremo Tribunal Federal. Sobre o Tribunal. Disponível em: http://www.stf. jus.br/portal/principal/principal.asp. Acesso em: 18 jul. 2010.

Venâncio Filho, Alberto. Das Arcadas ao Bacharelismo: 150 anos de ensino jurídico no Brasil. São Paulo: Perspectiva, 1977.

Wacquant, L. Esclarecer o Habitus. Trad. José Madureira Pinto e Virgílio Borges Pereira. Rev. Carla Augusto e pelo Autor. Educação e Linguagem, Ano 10, n. 16, pp. 63-71, jul/dez, 2007. 


\section{Jornais e Revistas:}

A Gazeta dos Tribunaes. Disponível em http://memoria.bn.br/DocReader/ docreader.aspx?bib=709492\&pasta=ano\%20184\&pesq=. Acesso em setembro de 2017.

A Gazeta Jurídica: Revista mensal de doutrina, jurisprudência e legislação. Disponível em: http://memoria.bn.br/DocReader/docreader. aspx?bib=234788\&pasta=ano\%20187\&pesq=. Acesso em setembro de 2017.

Ensaio Jurídico e Litterario. Disponível em: http://memoria.bn.br/DocReader/docreader.aspx?bib=821306\&pesq=. Acesso em setembro de 2017. 
